\title{
6
}

\section{Technological facilitation for decision-making in education}

\author{
D.W. Spuck, A.J. MacNeil, D.L. Prater, and D.B. Palumbo \\ University of Houston \\ Clear Lake, 2700 Bay Area Boulevard, Houston, Texas 77058 \\ USA \\ Phone: 713-283-3501 \\ Fax: 713-283-3509 \\ e-mail:SPUCK@CL.UH.EDU
}

\begin{abstract}
An alternative form of meeting environment known as Electronic Meeting Systems (EMS) is now possible through the application of information technology that attempts to make meetings more productive. Group involvement in decision making is consistent with current trends toward site-based management and total quality management. The movement toward collaborative decision making and group consensus building requires facilitation. Through the use of this technology, administrators have the opportunity and the support for issue identification and prioritization procedures, which facilitates achievement of group consensus.
\end{abstract}

\section{Keywords}

Educational management, electronic meeting systems, policy, problem solving

\section{INTRODUCTION}

Group decision making is very much a part of the democratic process and culture. Restructuring organizations by decentralization to site-based decision making is now the emerging management and organization model in both the public and private sectors (Barzelay, 1992; Katzenbach \& Smith, 1993; Lawler, 1986, 1992; Wohlstetter, Smyer, \& Mohrman, 1994). As our society evolves technologically, the work world increasingly becomes more complex, requires teamwork, and exists in a rapidly changing environment. Work that is simple, individual, and always predictable needs a hierarchical structure. Work that is complex, collegial, and uncertain tends to be decentralized and requires employee involvement, and commitment. The collective wisdom of a group can, in many instances, improve the quality of decision making. Conventional wisdom also advocates that participation in the decision process increases commitment for the decision. In a recent longitudinal study comparing group decisions to individual decisions, Watson, Michaelson and Sharp (1991) showed that groups 
scored higher than their best member by 70 percent at each point in time. The study also showed that as the group gained experience, best members became less important to the group's success.

Traditional meeting methods are currently under review, particularly in their ability to effectively and efficiently bring groups to consensus (Hitchings \& Cox, 1992; Paulus, Dzindolte, Poletes, \& Camacho, 1993). Educational leaders are constantly in search of the most efficient and effective meeting techniques and computer-based technologies have begun to provide effective tools to effect more productive meetings. These hardware/software combinations, commonly known as electronic meeting systems (EMS) have begun to find their way into a variety of educational environments (Aiken \& Riggs, 1993). Some strategies for group decision support are patterned after the nominal group process models of Delbecq and Van de Ven (1971; see also Spuck, 1976). EMS provides computer support for issue identification and prioritization procedures, which facilitates achievement of group consensus. Nunamaker and Briggs (1991) suggested that the major advantage is more time free from the demands of frequent - and often frustrating - meetings. Technology-mediated environments are designed to improve the productivity of many collaborative planning and decision making processes (RICIS, 1994).

Current practice increasingly involves collaborative methods and group consensus building in educational decision making. Nunamaker and his colleagues (Nunamaker, Dennis, Valacich, Vogel, \& George, 1991) have proposed that EMS improves group work in the following ways:

1. All participants can input their ideas simultaneously.

2. Opportunity for equal participation of all group members is provided.

3. Behavior that can impact negatively on group productivity is discouraged.

4. Large groups can work together effectively to provide more information, knowledge and skills to work on the task.

5. More techniques and methods are available for large groups to perform tasks.

6. External information is accessible for the group members.

7. An organizational memory is developed from meeting to meeting.

Nunamaker et al. (1991) also have presented a strategy for understanding EMS processes, focusing on the characteristics of the group to be involved in the process, the tasks to be completed, the context of the organization and culture, and the outcome to be achieved. These items provide a framework for evaluating and understanding this and other examples of EMS and establish an organization for a research agenda on system use (Spuck, Prater \& Palumbo, 1995).

Examples of issues for which EMS can provide assistance are defining school district planning priorities, identifying strategies for resolving specific problems such as improving school drop-out rates, setting priorities, formulating school policy, and designing curriculum. This paper describes the purpose and function of EMS as used to support decision making in respect of two different problems. The first is the redefinition of the graduate core curriculum for master's degree programs in a school of education and the second is an analysis of a case study used in the instructional program for school administrators.

\section{IMPORTANCE OF GROUP DECISION MAKING}

The continuing efforts toward decentralization and making the public schools more accountable and responsible, focus on the need for improved group decision making processes. Recently there have been studies that show that site-based management efforts have not resulted in the predicted change. Bimber's (1994) study for the Rand Corporation predicted that the decentralization movement will continue even though there 
is little success to show with decentralization to date. Bimber (1994) noted that the theory is appropriate but the process has been inadequate. Site-based management relocates the power, authority, and accountability of the organization to the people directly involved with providing the service or making the product. Mohrman, Lawler, and Mohrman (1992) argued that teachers do intellectually complex tasks, are most effective when working collegially or in teams, and face uncertainty in their day-to-day work. Therefore, a high-involvement and decentralized management strategy is appropriate for schools. Failure of the decentralization movement is rooted in the lack of empowerment of the mass of educators. Fullan (1996) focused attention on the failure of reform as a failure to involve enough people in the process. "This is why attempting to change the system directly, through regulation and structural reform does not work. It is people who change systems, through the development of new critical masses." (Fullan, 1996 , p. 423). The use of EMS would be a direct and pervasive means of involving greater numbers in the process of deciding.

Given the importance of good decisions and good decision making and the increasing numbers and groups of people who will now be involved in the decision process (e.g., site based decision making), facilitation is necessary. It is important to minimize poor decisions and poor decision making practices. There are and have been many times when groups have made bad decisions or when the conditions of information would warrant a different decision than the one made. Educators often tell stories that attest to the befuddled and bizarre decisions that come from school boards throughout North America. Listing examples of building design and location problems, personnel selection decisions or policy decisions that would boggle the mind are often the sport of educators as they gather in social situations at professional development meetings. There is no end to the stories and situations that have been the result of flawed decision making practices of groups responsible for educating our youth. There is also well documented evidence of poor decision making by other decision making groups that have fallen victims of "group think" and "escalating commitment" such as the Bay of Pigs fiasco of the Kennedy administration and the NASA Challenger Disaster.

\section{ELECTRONIC MEETING SYSTEMS}

Computer programs specifically designed to help in the group decision making process are now available. Best and prevailing practice increasingly involves collaborative methods and group consensus building. It also includes involvement of various interest groups, or representatives, of groups, in educational decision making.

EMS environments can be characterized by three essential components: (a) the meeting facility, (b) the electronic meeting software, and (c) the facilitation method used. This electronic meeting system works on a network of personal computers, usually one for each participant. Computers are arranged around a meeting table with each computer connected directly to a central computer that serves to coordinate and store data about the meeting. EMS facilities often also contain one or more large display screens for group viewing during discussion, brainstorming ideas and decision making (Nunamaker, et al., 1991).

There are a variety of EMS software tools currently available to support EMS environments. According to Johansen (1994), there currently are more than 100 software vendors developing more than 300 products that support some form of electronic meeting environments. Some examples of the meeting environments are Lotus Notes that distributes to many group members a variety of information quickly and easily. Examples of more collaborative environments are: Option Finder, Group Systems V, Vision Quest, and The Meeting Room.

While EMS environments offer the possibility of large productivity gains, such gains are not easily obtained and require a fundamental shift in the thinking of a group. The 
shift is linked to the manner in which the EMS are facilitated. A variety of meeting methods have been adapted to these EMS environments. Most EMS activities follow a common sequence:

1. A group leader meets with a facilitator to develop an agenda and to select Groupware tools.

2. Meetings generally begin with an idea generating activity using the electronic brainstorming tool.

3. Comments from idea generation are organized into a list of key issues using the idea organization tool.

4. The vote tool is used to prioritize the key issues.

5. The topic commenter tool is used to discuss the top issues (Nunamaker \& Briggs, 1991).

While the adoption of EMS technologies has not advanced much beyond the technology development and implementation stage, initial analysis indicated that in these environments there appears to be: (a) more attention placed on pre-meeting planning, (b) more material generated, (c) somewhat less verbal discussion, (d) more focus and intensity from both the group leaders and participants, (e) less "wasted" non-productive time, and (f) higher degrees of participant satisfaction with both the process and the decisions taken (Greene, DiPette, Palumbo, \& Wijesinghe, 1994).

\section{TWO RECENT EXPERIENCES USING EMS}

Given the need to involve the participants and those affected by decisions in the decision making process, as well as the inherent capability of erring in group decisions, the following studies were undertaken at the University of Houston - Clear Lake (UHCL). The EMS lab was used with educators for two very different types of decisions that demonstrate the diversity of situations in which EMS has capability for facilitating decision making. These two examples involve the use of EMS in redefining the master's-level graduate core, and student use in reaching consensus in a case study analysis.

\subsection{EMS Use in Redefining the Master's Degree Core}

For more than a decade, master's degree programs in education at the University of Houston -Clear Lake have included a set of four core courses that remained relatively stable over that time. The only significant change was that a computer literacy course replaced an educational psychology requirement about five years ago. While the content of specific courses was revised over time, the basic structure and philosophy of the core was not.

The task the faculty had was to undertake a complete reassessment of the graduate core; reopening the questions of whether a set of core experiences, to be included in all master's degree programs in the School of Education, still made sense, and if so, what outcomes should be included. A task force of seven faculty members, representing current core areas, as well as faculty members from master's degree programs served by the core, were appointed. The charge given to the task force requested: (a) a recommendation for courses and experiences that would be common to all graduate programs and therefore required of each master's degree student, (b) that the committee ensure that broad-based input was solicited, and (c) that they consider the use of the EMS lab in gathering input and reaching consensus.

While the actual plan to be followed evolved over time, the process that emerged may be seen as containing ten steps. These ten steps are outlined in Figure 1. Included as ini- 
tial input, Step 1, was that gained from forums with the faculty in each of our master's degree programs and with the faculty who currently taught courses in the present core. Faculty associated with each of the master's degree programs were asked to meet as a group prior to the open form and to identify for their program eight to ten major outcomes or challenges for future graduates; as a result 155 items were submitted.

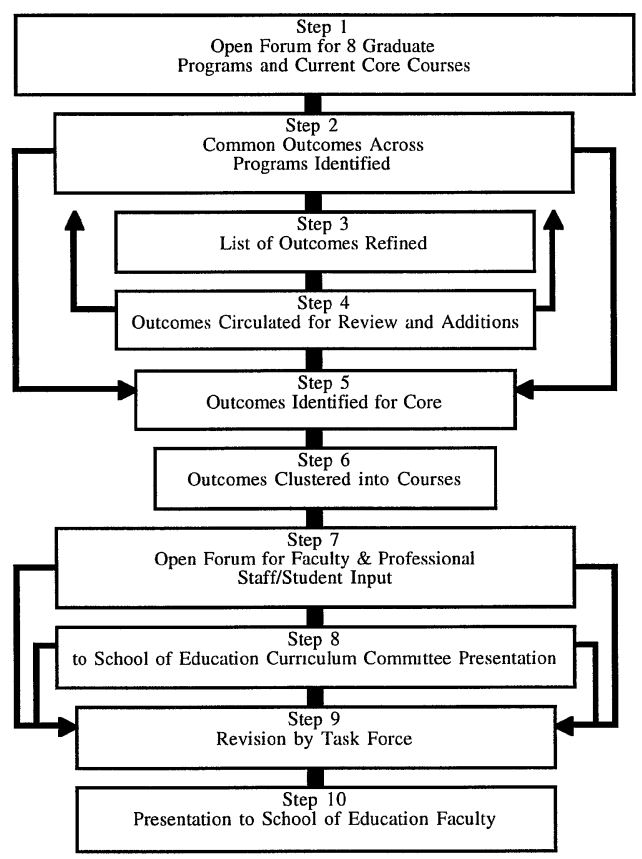

Figure 1

Graduate Core Review Process.

The following two steps, utilizing the EMS lab, identified those outcomes and challenges that were believed to be common to three or more of the master's degree programs, reducing the list to 91 items. Following discussion and comment, a vote was taken and items that four or more committee members identified as common to three or more programs were retained. Items that did not receive this level of committee support were deleted.

Next the list of common outcomes was refined to combine similar and eliminate duplicate items, to expand narrow items and become more specific about broad items, and try to begin to achieve a measure of consistency and parallelism in item statements; this process resulted in a reduction of the outcome list to a total of 41 items. For example, the items "issues related to understanding multicultural populations" and "understanding microcultures (e.g., gender, religion, exceptionality)" were seen by the committee as being included in another item, "model and encourage appreciation for students' cultural heritage, unique endowments, learning styles, interests and needs," and the former two items were eliminated from the list.

All faculty members in the School of Education were then invited to review the 41 items and to provide suggestions for additions, deletions, and rewordings to the list. Most of the suggestions provided rewordings of the outcomes and generally were 
incorporated. The other more substantive suggestions were discussed at length and the EMS lab was used by the task force to achieve agreement as to whether or not to add items to the list; as a result, one new item was included, for a total of 42 outcomes. In step five, the EMS lab was utilized to gain consensus from the task force as to which of the 42 outcomes were core responsibilities, and which were responsibilities of individual programs; 31 items remained on the list of core outcomes.

Until step six the idea of combining objectives into courses had been avoided, as it was clear that this is when the process would become highly political, as academic territory emerged as an issue. Even here, the term course was not used, as the committee was asked to create content "chunks", placing those outcomes together which seemed to share a similarity of content; but following the chunking of outcomes, the combining of these chunks into four clusters defined the structure of the courses to be proposed. Consensus of the task force members was achieved around these courses.

Step seven provided an opportunity for students and faculty to comment on the proposed master's degree core courses. Step eight formally presented the task force recommendation to the curriculum committee of the School of Education. Also in step eight, the task force considered various comments and suggestions that had been received and made final revisions in the recommendation. The task force recommendation was presented to the entire faculty for consideration and was approved unanimously for implementation.

\section{Comments and observation on EMS processes}

Typically academic considerations, such as defining a core, are ripe for political agendas and conflict; while these forces were apparent in this case, too, the graduate core recommended by the task force was approved overwhelmingly by the faculty as-awhole, and with a high level of esprit and camaraderie - a remarkable result and one in part attributable to the process followed.

The EMS lab was used to supplement activities that transpired over a period of seven months. While EMS software was helpful, it was used only at selected intervals within the process. The major EMS program features that were employed were voting, sorting, and the use of comment cards. Voting is used to gain group consensus (for example, this outcome should be the responsibility of the core). Sorting is the identification of items of similar content, that is, the grouping of outcomes into similar categories (for example, similar dusters of outcomes were sorted into courses). Comment cards allowed task force members to describe their interpretation of the meaning of a particular outcome and to explain why each outcome was a core responsibility or why it would be best delivered by an individual program.

\section{Key things learned from the process revolve around the following issues}

Issue \#1: The Facilitator. The facilitator must understand both the issue to be considered as well as the process to be followed in addressing the issue. It is important that the facilitator not get involved in the discussion and not be, or even be perceived, as having a position on the issues addressed. It is best that the facilitator not be well known by the program participants.

Issue \#2: The Importance of a Well-Developed Agenda. The participants were intrigued with the software. The initial visit to the lab was fascinating and the group looked forward to the sessions in the lab. There was a tendency, however, to want to move too quickly through the process (e.g., Let's take a straw poll since we can do it so easily). If you vote too quickly on issues, positions get polarized. It also seems that you can get too reductive in your thinking, moving too quickly to resolution. Due to the novelty of the software, there was a tendency to want to try all the options. It is important that the agenda be thoughtfully worked out in advance; which we did, as the task force chair met 
with the facilitator prior to each meeting and prepared the agenda. This agenda was shared at the onset and participants knew what to expect.

Issue \#3: Comment Cards. The comment cards were one of the most useful parts of the process, particularly those comments that participants directed back to each other's input. There were instances where comments continued to build and branch off an original comment, pointing out a "hot- issue that needed to be worked through." The comments also illustrated that we sometimes discover our own position about an issue through collective thinking (i.e., your idea triggers an idea in me that I might not otherwise have considered). The process was very generative in nature.

Issue \#4: Use the Lab as a Supplement. Carefully plan how and when you can benefit from using the lab. Don't be seduced into thinking it does all things for you. At some stages traditional group deliberations are better. Make it work for you, but don't get too enamored of the software and lab setting.

\subsection{Graduate Students Case Study: The process}

This investigation used a case study as the basis for creating a decision making situation. The case concerned an experienced high school principal newly assigned to a school that lacked leadership. The case focused on the difficulty he had in dealing with a recalcitrant secretary. A group of graduate students in the educational leadership program that were familiar with a case study approach used the EMS lab. Other students, also familiar with the case study approach, followed a traditional analysis approach to case studies.

The educational leadership class had 39 students; 13 students used the EMS, while the other 26 students stayed in their usual groups of five or six students. These five groups had the same case and were to follow the traditional case study approach. These groups were studied to determine whether problem identification would be similar.

The EMS used an approach based on the Nominal Group Technique. This approach is a refinement of brainstorming that focuses on generating alternatives and choosing one. This approach is recommended where group members fear criticism. The following steps were used: members silently list their ideas, all ideas are listed on chart with discussion allowed for clarification but no criticism, finally a written vote is taken (Van de Ven \& Delbecq, 1974). This process encourages members to pool their judgments in order to solve the problem and then determine a satisfactory course of action.

Using the EMS system students followed this agenda:

5:15 PM Introduction to the Case

5:20 PM Introduction to the EMS lab

5:50 PM Generate problems (Categorizer). Identify the problems faced by the Kingsville High School, \& the principal

6:20 PM Determine Agreement (Vote). Identify the crucial/important problems. (Multiple choice: top 15 problems)

7:20 PM Determine Agreement (Vote). The Rank order list of top 14 problems.

7:50 PM Generate Solutions (Categorizer). Generate suggestions/solutions to overcome problems [for the top five problems]

8:20 PM Identify the top most important problems (Vote). Identify the two most important problems [reviewing the solutions]

8:50 PM Identify Advantages/Disadvantages (Categorizer). Identify the advantages/ disadvantages of implementing each solution.

The process is one of brainstorming to identify the problem. The group of thirteen graduate students identified 61 problems. To succeed and get agreement on the identification of the problem that the case presented, the students were asked to vote to 
narrow the selection to the top fifteen. The sixty-one possible problems had many similarities about them and an attempt to group them together was not successful.

The group was then asked to vote and prioritize the fourteen selections. The sum of the rank ordering and the mean are calculated and the standard deviation from the mean is also provided. The ballot showed that most of the students identified the main problem as the lack of support from the Superintendent, but this result was not significantly more important that the other problems identified. The significance level is found by the program calculating the consensus threshold using Ventana's coefficient of consensus (VCC). The value of 1.00 represents complete consensus and the value of 0.00 represents no consensus. The VCC $=1.00-(($ STD / (high Limit - low limit $)) * 2)$. The significance 0.18 showed very little consensus, as a result of 0.65 would be considered significant. The lab assistant then narrowed the choices to five and the students voted. This time the VCC was calculated at 0.26 which again showed non significant agreement among the decision makers.

The next step in the process is to generate solutions. The most top five identified problems were presented for solutions. Problem one created forty-five solutions. Problem 2-15, solution, problem 3 -11. problem 4-11, problem 5-9. After identifying solutions for the problems they were asked to vote again on the critical problem. The students were then directed to predict by brainstorming the advantages and disadvantages of the solutions for the problems. Again there was a great deal of data that needed to be sorted.

\section{The outcome}

The identification of the problem with the EMS system focused on the Superintendent and his/her lack of support for the principal in handling the difficulty with the secretary. The other five groups of five or six students identified the problem as being a difficult secretary and the need for the principal to proceed with progressive discipline. The EMS students focused more on the problem of lack of leadership in the organization and the relationship between the principal and the superintendent. There is no one correct answer to case studies because a case reports the author's bias and all detail cannot be given; as well, the assumptions that the students make in determining the analysis cannot be controlled. Given these considerations it can still be seen that the use of EMS has a great deal of potential for overcoming problems with decision making. The fact that the EMS group identified the problem differently points to the potential of creativity in the decision-making process.

\section{THE ADVANTAGES OF USING EMS}

There is an overwhelming amount of data produced and easily sorted using the EMS system. The variety of ideas makes the group's work more focused on solving the problem rather than defending a solution. Olaniran (1994) made the observation that using electronic brainstorming produces significantly more fresh ideas. The use of EMS allows the calculation of the data to be produced by the system and the results are available throughout the meeting as well as in summary at the end of the session. A complete record of the meeting is available for analysis at the end of the meeting.

Using the EMS removes a major barrier of members seeing and hearing which ideas are whose. It encourages members of the decision making team to think and create solutions rather than to play the politics of supporting an ally or friend. Nelson \& Quick (1994) reported that the Boeing Company study of its meetings found that 20 percent of the team members did 80 percent of the talking. Using EMS frees members' participation and relationships become less important as the focus is on determining a best result. While the time taken to reach consensus on the case study took longer than it did for the traditional case study group, the number of problems identified and the 
number of solutions generated was much greater. In the traditional group, a member of the group emerged as a leader and shaped the work of the group in order to move to closure and likely shaped the conclusions in a direction acceptable to hime/her. Nelson \& Quick (1994) also reported from the Boeing study that the time needed to complete team projects was reduced by an average of 91 percent with an average cost saving in employee time of $\$ 6700$. The fact that there can be simultaneous input is a time saver. Members of the decision-making group are not having to stop their own inputs or observations because another member has the floor; all members of the group can talk at once and still be heard and recognized.

\section{SOME PROBLEMS USING EMS}

Using the EMS can be more time consuming than using the traditional method of working in a group on a case study. As noted, the groups not using the EMS reached their conclusions more quickly than the EMS student group. The anonymous nature of the meeting can also encourage frivolity and distract others from the task, although some humor may add to the meeting. Another problem with anonymity is that it encourages irresponsibility and the accountability for one's actions can be lost. Educational settings, because they often require public accountability, cannot always be anonymous.

\section{CONCLUSION}

Just as some decisions are best made by individuals and some by teams or groups; some decisions are better suited to the use of the EMS. Decisions that tend to be emotional, controversial or complex would best be served by the EMS. Decisions that will result in hurt feelings and poor relationships that can cause an organization to become dysfunctional could be best served by the EMS. Decisions that need to be made avoiding the groupthink phenomena can be well served by EMS. Meetings that require creative or better solutions can be enhanced through the use of EMS. Decisions that can be helped with quick results through rapid polling and immediate feedback with real time results can be enriched through EMS. The importance of having a complete record of the meeting also is a distinct advantage of the EMS. The entries as well as the process are recorded and able to be analyzed.

One purpose of encouraging the use of the EMS lab for the reconceptualization of the master's degree core was to provide a useful example of lab use which represented a real problem to our faculty; it was hoped that the outcome would be positive, both in process and result, which it was. It also was hoped that use of the EMS process would encourage the faculty to make use of the lab for other purposes, and in particular encourage its use with problems and issues affecting their field-based constituencies. This goal is beginning to be realized as the EMS lab has since been used in a local school district, and is now scheduled by a superintendent and school board to be used in establishing priorities for the coming year.

In summary, the EMS lab provides a viable option for securing broad-based group involvement in decision making. Medium-sized groups can work together efficiently, ideas can be generated, and highly charged or sensitive issues can be aired in relative anonymity. Voting and prioritization of ideas are facilitated. While we should be cautious not to overstate the benefits of EMS use, it appears that group problem solving and consensus building may be particularly appropriate areas in which to take advantage of this technology. 


\section{REFERENCES}

Aiken, M., \& Riggs, M. (1993) Using a group decision support system for creativity. Journal of Creative Behavior, 27, 28-35.

Barzelay, M. (1992) Breaking through bureaucracy: a new way for managing in government. University of California Press, Berkeley, CA.

Bimber, B. (1994) The de-centralization mirage: comparing decision-making arrangements in four high schools. Rand, Santa Monica, CA.

Delbecq, A.L., \& Van de Ven, A.H. (1971) A group process model for problem identification and program planning. Journal of Applied Behavioral Science, 7.

Fullan, M. G. (1996) Turning systematic thinking on its head. Phi Delta Kappan, 77(6), 420-423.

Greene, L., DiPette, P., Palumbo, D.B. and Wijesinghe, R. (1994) Electronic meeting systems. Paper presented at the Phi Delta Kappa Eighth Annual Research Conference, Houston.

Hitchings, G. and Cox, S. (1992) Generating ideas using randomized search methods: a method of managed convergence. Management Decision, 30, 58-61.

Johansen, R. (1994) Is there life after reengineering? Continuity: The organizational desire for the 1990s, in Conference proceedings from the Fifth Annual Groupsystems Users' Conference (ed. J. Ceridwen), Ventana Corporation, Tucson, AZ.

Katzenbach, J.R. and Smith, D.K. (1993) The wisdom of teams: creating the highperformance organization. Harvard Business School Press, Boston.

Lawler, E. III (1986) High involvement management. Jossey-Bass, San Francisco.

Lawler, E. III (1992) The ultimate advantage: creating the high involvement organization. Jossey-Bass, San Francisco.

Mohrman, S.A., Lawler, E. III, \& Mohrman, A.M. Jr. (1992) Applying employee involvement in schools. Education Evaluation and Policy Analysis, 14(4), 347-360.

Nelson, D.L. and Quick, J.C. (1994) Organizational behavior: foundations realities and challenges. West Publishing Company: St. Paul, MN.

Nunamaker, J.F. and Briggs, R.O. (1991) Groupware user experience: ten years of lessons with Group Systems. Center for the Management of Information, University of Arizona, Tucson, AZ.

Nunamaker, J.F., Dennis, A.R., Valacich, J.S., Vogel, D.R. and George, J.F. (1991) Electronic meeting systems to support group work. Communications of the ACM, 34(7), 40-61.

Olaniran, B.A. (1994) Group performance in computer-mediated and face-to-face communication media. Management Communication Quarterly, 7(3), 256-281.

Paulus, P.B., Dzindolte, M.T., Poletes, G. and Camacho, L.M. (1993) Perception of performance in group brainstorming: The illusion of group productivity. Personality and Social Psychology Bulletin,19(1), 78-89.

RICIS (Research Institute for Computing and Information Systems) (1994) GSS Research Lab furthers the spirit of collaborative effort. RICIS Review, 6(1), 4-5,8.

Spuck, D.W. (1976) Evaluation for effective decision making, in The principal and individually guided education (eds. J.M. Lipham \& M.J. Fruth), Addison Wesley, Reading, MA.

Spuck, D.W., Prater, D.L. and Palumbo, D.B. (1995) Using electronic meeting system support in the design of the graduate core curriculum. Educational Technology: Research and Development, 43(2), 71-78.

Van de Van, A. and Delbecq, A. (1974) The effectiveness of nominal, Delhi and intergroup decision-making processes. Academy of Management Journal, 17(4), 605-621. 
Watson, W., Michaelson, L. K. and Sharp, W. (1991) Member competence, group interaction and group decision making: a longitudinal study. Journal of Applied Psychology, 76(6), 803-809.

Wohlstetter, P., Smyer, R. and Mohrman, S.A. (1994) New boundaries for schoolbased management: the high involvement model. Educational Evaluation and Policy Analysis, 16(3), 268-286.

\section{BIOGRAPHIES}

Dennis W. Spuck is dean of the School of Education and professor of foundations and educational leadership.

Angus J. MacNeil is an assistant professor of educational leadership.

Doris L. Prater is associate dean and professor of educational foundations.

David B. Palumbo is an associate professor of instructional technology.

All are at the University of Houston - Clear Lake and interested in applications of group decision support systems to problems and issues in teaching and policy development. 